EGU2020-19897

https://doi.org/10.5194/egusphere-egu2020-19897

EGU General Assembly 2020

(c) Author(s) 2020. This work is distributed under

the Creative Commons Attribution 4.0 License.

\title{
The tectonic and volcanic evolution of the Mangatolu Triple Junction
}

\author{
Rebecca Mensing ${ }^{1,4}$, Margaret Stewart ${ }^{2}$, Mark Hannington ${ }^{1,3}$, Alan Baxter ${ }^{3}$, and Dorothee \\ Mertmann ${ }^{4}$ \\ ${ }^{1}$ Marine Mineral Resources, Geomar - Helmholtz Centre for Ocean Research Kiel, Kiel, Germany \\ ${ }^{2}$ Department of Earth and Environmental Sciences, Mount Royal University, Calgary, Canada \\ ${ }^{3}$ Department of Earth and Environmental Sciences, University of Ottawa, Ottawa, Canada \\ ${ }^{4}$ Geodynamics, Martin-Luther-University Halle-Wittenberg, Halle (Saale), Germany
}

The Mangatolu Triple Junction (MTJ) is an intraoceanic back-arc spreading center that is host to at least 3 distinct hydrothermal systems. It is located in the NE Lau Basin, which opened due to rollback of the Pacific plate along the Tonga-Kermadec trench. At the MTJ, three spreading centers meet in a ridge-ridge-ridge (RRR)-type triple junction separating the Tonga plate in the east, the Niuafo'ou microplate in the southwest, and an unnamed microplate in the north. The MTJ is directly linked to the formation and evolution of the Northeast Lau microplate mosaic, as plate fragmentation inevitably results in the formation of triple junctions, but it remains unclear whether the spreading centers are the drivers of plate fragmentation or a consequence of stress relocation related to microplate rotation. Detailed investigation of the geology and structural setting of the MTJ therefore provides valuable insight into the development in the northeast Lau Basin. Here we present the first comprehensive 1:200,000 geological map of the MTJ, based on a compilation of marine geophysical data (hydroacoustics, magnetics, and gravity) derived from 7 research cruises that have investigated the region between 2004 and 2018. Analysis of the mapped geological formations at the MTJ shows the importance of relict arc crust originating from the Tofua Arc in the architecture of the triple junction, which includes three stages of back-arc crust development and extensive off-axis volcanism. The spreading centers along each arm of the MTJ exploit pre-existing crustal weaknesses, interpreted to have formed during initial Lau Basin opening. A reconstruction of the basin opening, based on the mapped features and published spreading rates, revealed that initiation of the MTJ commenced approximately 180,000 years ago, consistent with the very recent and ongoing dynamic evolution of the NE Lau Basin and emerging microplate mosaic. Intersecting fabrics indicate sequential evolution of the 3 arms of the triple junction, with extension along the northeast arm dominant in the early history and more recent extension along the southern and western arms. The results of this study contribute to our growing understanding of the tectonic framework of the northeast Lau Basin and the role of triple junctions in microplate formation. 